\title{
Fine Structural Particularities of the Plasmodia and Myxospores of an Ortholinea sp. Infecting the Urinary Bladder of Teleost Fish in the Amazon River
}

\author{
Edilson Matos ${ }^{1}$, Sónia Rocha ${ }^{2,3}$, Graça Casal $^{3,4}$, Patrícia Matos ${ }^{5}$, Elsa Oliveira ${ }^{2}$, Saleh Al-Quraishy ${ }^{6}$ and \\ Carlos Azevedo $2,3,6$ \\ 1. Carlos Azevedo Research Lab., Federal Rural University of Amazonia (UFRA), Belém, PA, Brazil. \\ 2. Lab. Cell Biology, Institute of Biomedical Sciences, University of Porto (ICBAS/UP), Porto, Portugal. \\ 3. Lab. Animal Pathology, Interdisciplinary Center of Marine and Environmental Research, University of \\ Porto (CIIMAR/UP) Porto, Portugal. \\ 4. Dept. of Sciences, High Institute of Health Sciences-North, CESPU, Gandra, Portugal. \\ ${ }^{5 .}$ Edilson Matos Research Lab., Federal University of Pará (UFPA), Belém, PA, Brazil. \\ 6. Zoology Dept., College of Sciences, King Saud University, Riyadh, Saudi Arabia.
}

Microparasites of the class Myxosporea Bütschli, 1881 display a two-host life cycle that usually involves a vertebrate host and an invertebrate host of the phylum Annelida. The vertebrate host is typically a fish, but other aquatic-associated animals such as turtles, waterfowl and amphibians are also reported as hosts. Some of these microparasites have been reported as lethal for their hosts, thus having prejudicial impact in many socio-economic activities, and more specifically in the aquaculture industry [1]. Species of the genus Ortholinea Shulman, 1962 are mostly coelozoic in the excretory system of marine fish, with the exception of Ortholinea africanus, which is known to parasitize the Nile tilapia Oreochromis niloticus [2]. The latter was described without the use of electron microscopy, making this the first ultrastructural study of a freshwater Ortholinea sp.

Specimens of the freshwater teleost fish Aequidens plagiozonatus Kullander, 1984 (Brazilian common name "acará pixuna") were collected from the lower Amazon region near the city of Peixe Boi, State of Pará, Brazil. Fish were anaesthetized with MS 222 (Sandoz Laboratories) and dissected for the analysis of several organs and tissues using a light microscope. Plasmodia and free myxospores detected in the urinary bladder were prepared for transmission electron microscopy [3].

Semithin sections showed numerous disporic plasmodia attached to the epithelium of the urinary bladder (Fig. 1a). Ultrathin sections further revealed that the cellular membrane of the plasmodia riddled by peripheral projections (Figs $1 \mathrm{~b}$ and c). Myxospores were subspherical in valvular view and ellipsoidal in sutural view, measuring $\sim 9.0 \mu \mathrm{m}$ in length and $\sim 9.2 \mu \mathrm{m}$ in width $(n=25)$. The wall of the myxospores was comprised by two symmetric valves, which presented numerous superficial ridges and were united along an irregular sutural line (Fig. 1d). Within the myxospores, two equal subspherical polar capsules $(\sim 6.4 \times 4.6 \mu \mathrm{m})$ presented divergent orientation and opened to opposite sides of the suture line. Each polar capsule contained a polar filament coiled in 3-4 turns.

The morphometric and ultrastructural features of the plasmodia and myxospores, combined with host specificity, aquatic environment and geographic area, suggests this microparasite as a possible new species of the genus Ortholinea. However, a molecular identification is required to ascertain this taxonomic setting [4]. 


\section{References:}

[1] J. Lom and I. Dyková, Folia Parasitologica 53 (2006), p. 1.

[2] F. Abdel-Ghaffar et al., Parasitology Research 103 (2008), p. 1197.

[3] C. Azevedo et al., Diseases of Aquatic Organisms 85 (2009), p. 41.

[4] The authors acknowledge funding from: FCT within the scope of the Ph. D. fellowship grant attributed to S. Rocha (SFRH/BD/92661/2013); the project EUCVOA (NORTE-07-0162-FEDER000116); the Foundation A. Almeida; CAPES; CNPq; SISBIO-ICMBIO/IBAMA; and project no. 002 of King Saud University, Riyadh, Saudi Arabia.
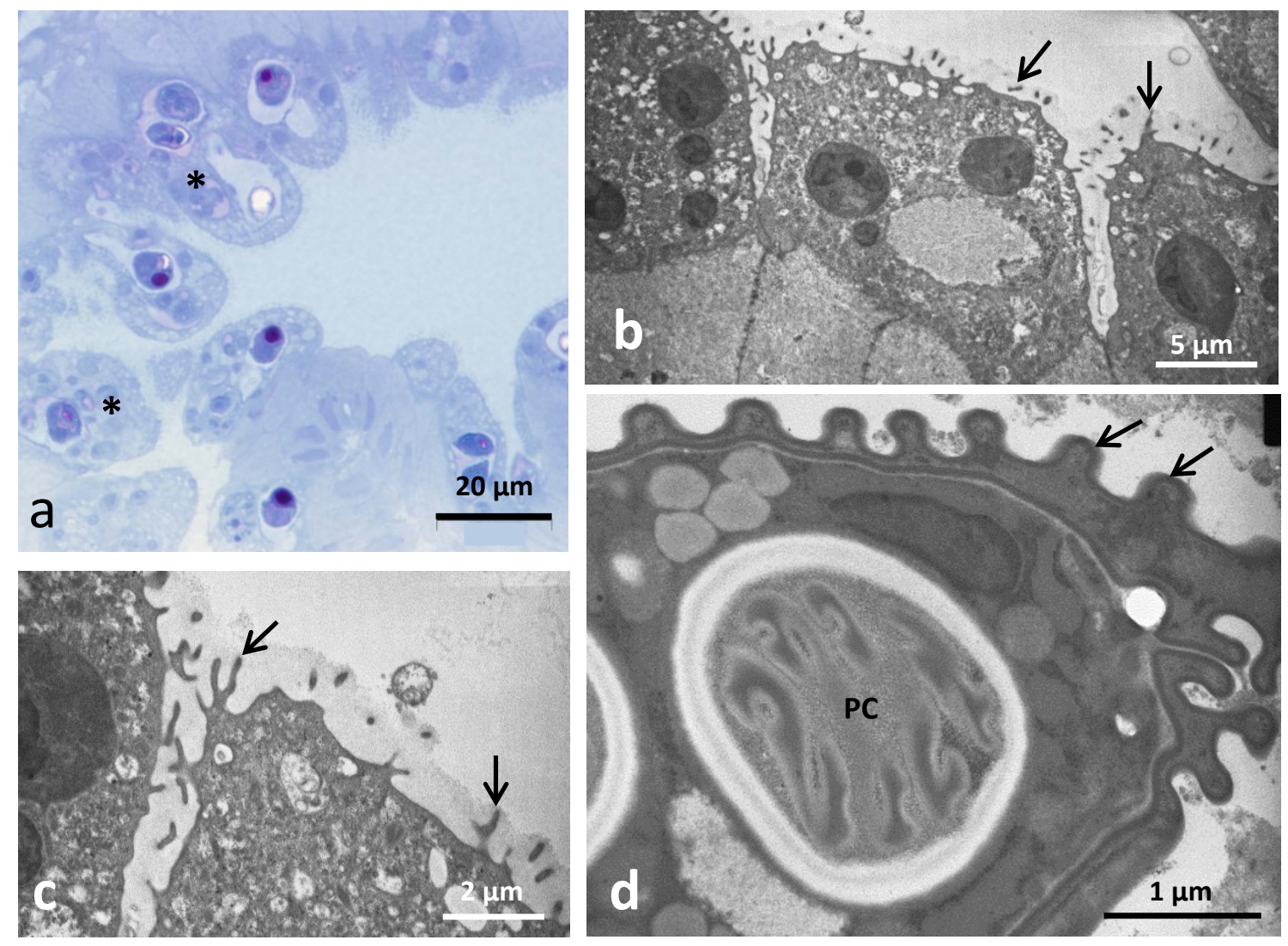

Figure 1. (a) Semithin section showing several disporic plasmodia (*) closely attached to the urinary bladder wall. (b) Ultrastructure of the plasmodia attached to the urinary bladder wall. Notice the peripheral projections (arrows). (c) Ultrastructural detail of the peripheral projections (arrows) covering the cellular membrane of a plasmodium (P). (d) Ultrastructural transverse section of a polar capsule (PC) showing its organization, namely of the wall and the polar filament sections. Notice the external ridges of the myxospores wall (arrows). 